\title{
Analysis of transfusion of blood and blood products and their utilization pattern at department of obstetrics of tertiary care hospital
}

\author{
Dipti C. Vasava, Rajal V. Thaker*, Aditi A. Tyagi, Foram P. Patel
} Department of Obstetrics and Gynecology, SCL Hospital, Smt. NHL Municipal Medical College, Ahmedabad,
Gujarat, India

Received: 25 October 2019

Accepted: 19 November 2019

*Correspondence:

Dr. Rajal V. Thaker,

E-mail: rvtpds@gmail.com

Copyright: () the author(s), publisher and licensee Medip Academy. This is an open-access article distributed under the terms of the Creative Commons Attribution Non-Commercial License, which permits unrestricted non-commercial use, distribution, and reproduction in any medium, provided the original work is properly cited.

\section{ABSTRACT}

Background: In developing countries, nutritional anaemia and obstetric complications are leading causes of transfusion of blood and blood products. The study was aimed to analyse utilization pattern and to identify the indications of transfusion of blood and blood products in obstetrics and to study outcome and management of pregnancy in patients who required blood and/or blood products.

Methods: This retrospective study was carried out at department of obstetrics of tertiary care teaching hospital from September 2018 to November 2018 and data was collected from all patients who had received transfusion of blood and/or blood products for any obstetric cause.

Results: A total of $164(6.8 \%)$ patients received blood and blood products transfusion. Department of obstetrics utilized maximum units of blood and FFP whereas PRC utilization was second highest. There were 62(37.8\%) of patients who had not taken any antenatal care, whereas 64(39.0\%) patients had less than 4 antenatal visits. Three most common indications for transfusion of blood and blood products were $63.4 \%$ in nutritional anaemia, $17.1 \%$ in obstetric haemorrhage and $11.6 \%$ in first trimester complications.

Conclusions: Three most common indications for transfusion were nutritional anaemia, obstetric haemorrhage and first trimester complications. Majority of patients had inadequate or no antenatal care. Early and regular antenatal care, early diagnosis and management of high-risk pregnancies and obstetric complications, institutional delivery can reduce the rate of transfusion of blood and blood products.

Keywords: Blood and blood products in obstetrics, Blood transfusion, Nutritional anaemia in pregnancy, Obstetric haemorrhage

\section{INTRODUCTION}

Blood transfusion is considered as one of the eight essential components of comprehensive emergency obstetric care, which has been shown to reduce the maternal mortality rates. ${ }^{1}$

In developing countries like India, nutritional anaemia and obstetric complications are leading causes of blood and blood products transfusion in obstetrics. Here prevalence of under nutrition and nutritional anaemia is very high; hence minimal amount of blood loss may lead to haemorrhagic shock. Abortion, ruptured ectopic pregnancy, self-ingestion of abortion pills, accidental haemorrhage and post-partum haemorrhage (PPH), bleeding during dilatation and evacuation (D/E) and caesarean section, adherent placenta, rupture uterus, disseminated intravascular coagulation (DIC), dengue and HELLP syndrome require transfusion of blood and/or blood products.. Acute obstetric blood loss is 
usually unpredictable and sudden where good haemoglobin level of patients is very important for preventing maternal morbidity and mortality.

The utilization of blood in maternity hospital mainly depends on the number of deliveries and number of highrisk cases admitted. Many a times, there is shortage of blood in the blood banks, as the blood collection is much less than the blood requirement. Advanced blood bank technology and availability of blood components help in optimal utilization of scarce blood resources. Blood transfusion does carry risk of transmission of infections and anaphylactic reactions. Various academic bodies have put forth the guidelines for rational use of blood in Obstetrics. Health professionals must understand the importance of judicious use of blood. ${ }^{2}$

This study was aimed to analyse utilization pattern and to identify the indications of transfusion of blood and blood products in obstetrics and to study outcome and management of pregnancy in patients who required blood and/or blood products.

\section{METHODS}

After due permission from institutional review board of our institute, this retrospective study was carried out at department of obstetrics of tertiary care teaching hospital for three months (September 2018 to November 2018) and data was collected from hospital records of all patients who had received transfusion of blood and/or blood products for any obstetric cause.

The study population included emergency as well as registered patients and urban as well as rural pateints. Patients' demographic details like age, education, residence, socioeconomical class were collected. Patients' obstetric history, number of antenatal visits, indications and timing of transfusion (whether antenatal/intranatal/postnatal), management of pregnancy and pregnancy outcome were also noted.

\section{Inclusion criteria}

- All patients who were admitted in department of obstetrics which included patients of pregnancy, delivery and post-partum period and required blood and/or blood components.

\section{Exclusion criteria}

- All patients who didn't require blood and/or blood products.

\section{Statistical analysis}

Data was collected from the case papers and also from records of blood bank. Data was analyzed by appropriate statistical tool.

\section{RESULTS}

During the study period, there were total of 2412 admissions in antenatal ward and labour room. Out of these $164(6.8 \%)$ of patients received blood and/or blood products.

Table 1: Socio-demographic details $(\mathrm{N}=164)$.

\begin{tabular}{|lll|}
\hline Socio-demographic details & Number & $\%$ \\
\hline Age (years) & \multicolumn{2}{l|}{} \\
\hline$<20$ & 4 & 2.3 \\
\hline $21-24$ & 58 & 35.4 \\
\hline $25-30$ & 78 & 47.6 \\
\hline $31-34$ & 17 & 10.4 \\
\hline $35-40$ & 7 & 4.3 \\
\hline Education & & \\
\hline Illiterate & 46 & 28.1 \\
\hline Primary & 67 & 40.7 \\
\hline Secondary & 38 & 23.2 \\
\hline Higher secondary & 8 & 4.9 \\
\hline Graduate & 2 & 1.1 \\
\hline Postgraduate & 3 & 1.7 \\
\hline Socio-economic class & & \\
\hline Middle & 13 & 7.9 \\
\hline Lower & 151 & 92.1 \\
\hline Residence & & \\
\hline Rural & 7 & 4.3 \\
\hline Urban & 157 \\
\hline Gravidity & & \\
\hline Primi & 34.7 \\
\hline Multi & 130 \\
\hline
\end{tabular}

As per data collected from the blood bank at our hospital, total 790 units of blood were dispatched during the study period. Out of these maximum units 281 (35.6\%) were utilised in the department of obstetrics. Department of paediatrics, medicine, surgery, orthopaedics, plastic surgery, pulmonary medicine and dermatology utilised 140 (17.7\%), 137 (17.3\%), 120 (15.2\%), 56 (7.1\%), 51 $(6.5 \%), 4(0.5 \%)$ and $1(0.1 \%)$ respectively.

Table 2: Antenatal visits $(\mathrm{N}=164)$.

\begin{tabular}{|lll|}
\hline Antenatal visits & Number & $\%$ \\
\hline Nil & 62 & 37.8 \\
\hline$<4$ & 64 & 39.0 \\
\hline$>4$ & 38 & 23.2 \\
\hline
\end{tabular}

During the study period, total 290 units of fresh frozen plasma (FFP) were utilized. Out of these maximum units were utilised in department of obstetrics, 97 (33.4\%). Department of medicine, paediatrics and surgery utilised $75(25.9 \%), 52(17.9 \%)$ and $66(22.8 \%)$ respectively.

During the study period, total 613 units of platelet rich concentrate (PRC) were dispatched. Out of these, 131 $(21.4 \%)$ units were utilized for patients of department of 
obstetrics. Department of medicine, paediatrics and surgery utilised $371(60.5 \%), 76(12.4 \%)$ and $35(5.7 \%)$ units respectively.

Hence, during the study period, department of obstetrics utilized maximum units of blood and FFP whereas PRC utilisation was second highest.

As shown in Table 1, majority of the patients 78 (47.6\%) belonged to the age group of 25-30 years. Primary, secondary, higher secondary, graduate, postgraduate education were attained in $67(40.7 \%), 38(23.2 \%), 8$ (4.9\%), $2(1.1 \%), 3(1.7 \%)$, respectively and $46(28.1 \%)$ patients were illiterate. Most of the women $151(92.1 \%)$ belonged to lower socio-economical class. Majority of the patients came to hospital were residing in urban areas 157 (95.7\%). Among all patients primi, second and multipara were $34(20.7 \%), 60$ (36.6\%), $70(42.7 \%)$ respectively.

As shown in Table 2, there were 62 (37.8\%) of patients who came as emergency admissions in the labour room and had not taken any antenatal care, whereas $64(39.0 \%)$ patients had less than 4 antenatal visits. Only 38 (23.2\%) patients had more than or equal to 4 antenatal visits.

Table 3: Transfusion period $(\mathrm{N}=164)$.

\begin{tabular}{|lll|}
\hline Transfusion period & Number & $\%$ \\
\hline Antepartum & 65 & 39.6 \\
\hline $1^{\text {st }}$ Trimester & 17 & 10.3 \\
\hline $2^{\text {nd }}$ Trimester & 12 & 7.3 \\
\hline $3^{\text {rd }}$ Trimester & 36 & 22.0 \\
\hline$<37$ weeks & 3 & 1.8 \\
\hline$>37$ weeks & 33 & 20.2 \\
\hline Intrapartum & 33 & 20.2 \\
\hline Postpartum & 66 & 40.2 \\
\hline
\end{tabular}

As shown in Table 3, 65 (39.6\%) patients received blood transfusion during antepartum period and out of these blood transfusions was given during first trimester, second trimester and third trimester in $17(10.3 \%), 12$ $(7.3 \%)$ and $36(22.0 \%)$ patients respectively.

In $3^{\text {rd }}$ trimester, majority $33(20.2 \%)$ transfusions were done after 37 weeks of gestation. Intrapartum and postpartum transfusions were given in 33 (20.2\%) and 66 $(40.2 \%)$ patients respectively.

As shown in Table 4, 104 (63.4\%) patients of nutritional anaemia who received blood,5 patients also had gestational hypertension and 2 patients had eclampsia. Transfusion was given in $19(11.6 \%)$ of patients of first trimester complications. Indications of transfusions were incomplete abortion, self-ingestion of abortion pills, ruptured ectopic and complete abortion in $9(5.5 \%), 5$ (3.1\%), $3(1.8 \%)$ and $2(1.2 \%)$ patients respectively.
Table 4: Indication of transfusion $(\mathrm{N}=164)$.

\begin{tabular}{|lll|}
\hline Indication of transfusion & Number & $\%$ \\
\hline Nutritional anaemia (Total) & $\mathbf{1 0 4}$ & $\mathbf{6 3 . 4}$ \\
\hline Anaemia & 97 & 59.1 \\
\hline $\begin{array}{l}\text { Anaemia with gestational } \\
\text { hypertension }\end{array}$ & 5 & 3.1 \\
\hline Anaemia with eclampsia & 2 & 1.2 \\
\hline 1 Trimester complications (Total) & $\mathbf{1 9}$ & $\mathbf{1 1 . 6}$ \\
\hline Incomplete abortion & 9 & 5.5 \\
\hline Self-ingestion of abortion pills & 5 & 3.1 \\
\hline Ruptured ectopic pregnancy & 3 & 1.8 \\
\hline Complete abortion & 2 & 1.2 \\
\hline Obstetric haemorrhage (Total) & $\mathbf{2 8}$ & $\mathbf{1 7 . 1}$ \\
\hline Placenta praevia & 9 & 5.5 \\
\hline Placenta praevia with pre-eclampsia & 1 & 0.6 \\
\hline Abruptio placenta & 4 & 2.5 \\
\hline Abruptio placenta with preeclampsia & 2 & 1.2 \\
\hline Placenta accreta & 2 & 1.2 \\
\hline Atonic PPH & 10 & 6.1 \\
\hline DIC (Total) & $\mathbf{5}$ & $\mathbf{3 . 1}$ \\
\hline DIC with HELLP and eclampsia & 1 & 0.6 \\
\hline $\begin{array}{l}\text { DIC with Hepatorenal shut down } \\
\text { and HELLP }\end{array}$ & 1 & 0.6 \\
\hline DIC with HEV positive & 1 & 0.6 \\
\hline DIC with septicaemia & 1 & 0.6 \\
\hline $\begin{array}{l}\text { DIC with abruptio placenta, IUD, } \\
\text { eclampsia }\end{array}$ & 1 & 0.6 \\
\hline Gestational thrombocytopenia & $\mathbf{3}$ & $\mathbf{1 . 8}$ \\
\hline Dengue & $\mathbf{3}$ & $\mathbf{1 . 8}$ \\
\hline HELLP syndrome (Total) & $\mathbf{2}$ & $\mathbf{1 . 2}$ \\
\hline HELLP with eclampsia (PRESS) & 1 & 0.6 \\
\hline HELLP with eclampsia & 1 & 0.6 \\
\hline
\end{tabular}

Total $28(17.1 \%)$ patients had obstetric haemorrhage, placenta praevia was present in $10(6.1 \%)$ patients, out of these $1(0.6 \%)$ had pre-eclampsia. Abruptio placenta was present in $6(3.7 \%)$ patients, out of these $2(1.2 \%)$ patients had pre-eclampsia also. Placenta accreta was present in $2(1.2 \%)$ patients and $10(6.1 \%)$ patients had atonic $\mathrm{PPH}$.

Other less common indications of transfusion were DIC in $5(3.1 \%)$ patients, gestational thrombocytopenia and dengue in $3(1.8 \%)$ each and HELLP syndrome in 2 $(1.2 \%)$ patients.

During the study period, vaginal delivery occurred in 65 $(39.6 \%)$ patients, out of these full-term and pre-term deliveries were $40(24.4 \%)$ and $25(15.2 \%)$ respectively.

LSCS was performed in $53(32.3 \%)$ patients, out of these full-term and pre-term LSCS were $28(17.1 \%)$ and 25 $(15.2 \%)$ respectively. Out of 121 babies, 113 (93.4\%) were live, $8(6.6 \%)$ died in utero, admissions in neonatal intensive care unit (NICU) were 24 and 10 babies expired in neonatal period. 


\section{DISCUSSION}

In present study, majority of patients $136(83 \%)$ were in age group of 21-30 years of age and majority of patients $130(79.3 \%)$ were multigravida. Fazal $\mathrm{S}$ et al, have reported majority patients in age group of 20-29 years and almost equal number of primi $(49.2 \%)$ and multi $(50.8 \%)$ gravida patients. ${ }^{3}$

In our study, majority of the patients, 157 (95.7\%) who required blood transfusion were from urban areas. Singh S. et al, have reported $53.5 \%$ and $46.5 \%$ from urban and rural areas respectively. ${ }^{1}$ In our study majority of the patients $151(92.1 \%)$ were from lower socio-economical class. Singh et al, have reported $42 \%$ and $39 \%$ patients from middle and lower socio-economic class. ${ }^{1}$

In present study, $62(37.8 \%)$ of the patients were emergency admissions in the labour room, where as 64 $(39.0 \%)$ patients had less than 4 antenatal visits. Only 38 (23.2\%) patients had more or equal 4 antenatal visits which fulfil the World Health Organization's focused antenatal care model criteria. ${ }^{4}$ The study of Madhushree D et al has reported $30.9 \%$ of unregistered patients. ${ }^{5}$

In present study, antepartum, intrapartum and postpartum transfusions were 65 (39.6\%), $33(20.2 \%)$ and $66(40.2 \%)$ respectively. Hence, peripartum transfusion was $60.4 \%$. Fazal $\mathrm{S}$ et al, have reported antepartum and peripartum transfusion in $27 \%$ and $73 \%$ respectively. ${ }^{3}$ Madhushree D et al have reported that, antepartum transfusion 161 $(78.9 \%)$ was more than intrapartum $28(13.7 \%)$ and postpartum $15(7.3 \%)$ transfusions. ${ }^{5}$ In present study, out of 65 antenatal transfusions, almost half of the patients 33 $(50.7 \%)$ received transfusion in term gestation i.e. $>37$ weeks, which corresponds to Kawthalkar A et al, study where majority of patients $(41.4 \%)$ who received blood transfusion were having $>37$ weeks of gestation. ${ }^{6}$

During the study period, out of all departments of our tertiary care hospital, department of obstetrics utilized maximum units of blood and FFP whereas PRC utilization was second highest. Out of 164 patients, 11 patients were given FFP (placenta accreta - 2, Gestational thrombocytopenia - 1, DIC - 5, Dengue - 1, HELLP - 2) and 15 patients were given PRC ( placenta accrete - 2, Gestational thrombocytopenia - 2, DIC - 5, Dengue - 3, HELLP- 3).

During the study period, most common indication for blood transfusion was nutritional anaemia in $63.4 \%$ of patients. Kawthalkar A et al, Fazal $\mathrm{S}$ et al, and Madhushree D et al, have reported $63.8 \%, 61.6 \%$, and $58.4 \%$ patients of nutritional anaemia who required blood transfusion. ${ }^{3,5,6}$ As per National Family Health Survey 4 (NFHS 4), pregnant women who were anaemic in state of Gujarat and India were $51.3 \%$ and $50.4 \%$ respectively. ${ }^{7}$ Urban- Rural ratio of pregnant women who were anaemic in Gujarat and India was $47.2 \%-54.2 \%$ and $45.8 \%-52.2 \%$ respectively. The percentage of pregnant women who were anaemic in NFHS-3 data was $60.8 \%$ in Gujarat and $57.9 \%$ in India. Hence, there has been an improvement in status of anaemia but still we have a long way to go as far as correction of anaemia is concerned and it can be attained by regular ANC along with treatment of malaria and worm infestations, food choices and food preparations so, that iron is absorbed properly. Early diagnosis of anaemia can reduce the need of blood transfusion as early detection of anaemia can be treated with oral or parenteral iron therapy.

In present study, second and third most common indications for transfusion of blood and blood products were obstetric haemorrhage and first trimester complications in $17.1 \%$ and $11.6 \%$ of patients respectively. Madhushree D et al, Singh S et al and Bangal VB et al have reported $15.2 \%, 11.8 \%$ and $10.2 \%$ of patients of first trimester complications who required blood transfusion respectively., ${ }^{1,2,5}$ Bangal VB et al, Singh et al and Madhushree D et al have reported $34.3 \%$, $25.1 \%$ and $19.6 \%$ of patients who required blood and blood products for obstetric haemorrhage. ${ }^{1,2,5}$ Kawthalkar A et al have reported that transfusion was required in $24.1 \%$ and $12.1 \%$ of patients of first trimester complications and obstetric haemorrhage respectively. ${ }^{6}$ Adukauskienè et al have reported that major obstetric hemorrhage remains the leading cause of maternal morbidity and mortality worldwide. $^{8}$

In present study, $6.8 \%$ of patients received blood and/or blood products. Chowdhury $\mathrm{F}$ et al have reported $9.2 \%$ of their patients who required transfusion. ${ }^{9}$

In present study, were no transfusion reactions (BTRs) whereas in Madhushree D et al have reported 9 patients out of 204 who suffered from BTRs. ${ }^{5}$

In present study, there was one maternal mortality of a multiparous patient who had delivered at home and developed septicaemia and DIC. In our study out of 121 babies, 114 (93.4\%) were live, 8 were IUD and 10 babies expired in neonatal period. Patel VP et al, have reported 53 IUD and 27 neonatal deaths. ${ }^{10}$

Single unit blood transfusion, literally has no meaning in obstetrics and thus should be avoided. Similarly, whole blood transfusion should be avoided as much as possible. The treating obstetrician usually decides decision of blood transfusion, its time, type, and quantity. Timely consultation or second opinion from anesthesiologist, intensivist or physician help in correct decision-making regarding type and amount of blood to be replaced. ${ }^{2}$

\section{CONCLUSION}

Three most common indications for transfusion were nutritional anaemia, obstetric haemorrhage and first trimester complications. Majority of patients had inadequate or no antenatal care. Counselling and prevention of anaemia since adolescence can reduce the prevalence of anaemia in women who become pregnant 
later. Early and regular ante natal care, early diagnosis of anaemia and its management, early diagnosis and management of high-risk pregnancies and obstetric complications, institutional delivery, active management of third stage of labour can reduce the rate of transfusion of blood and blood products. There are risks involved in transfusion. Hence, judicious and optimum use of blood and blood products is recommended.

\section{ACKNOWLEDGMENTS}

Authors would like to thank Superintendent of SCL Hospital and Dean of Smt. NHL Municipal Medical College.

Funding: No funding sources Conflict of interest: None declared

Ethical approval: The study was approved by the Institutional Ethics Committee

\section{REFERENCES}

1. Singh S, Sinha P, Yadav G, Gupta U, Tyagi P. Transfusion practices in obstetrics and gynaecology in a tertiary care center. Int $\mathbf{J}$ Reprod Contracept Obstet Gynecol. 2016;5:831-4.

2. Bangal VB, Gavhane SP, Aher KH, Bhavsar DK, Verma PR, Gagare SD. Pattern of utilization of blood and blood components in obstetrics at tertiary care hospital. Int J Reprod Contracept Obstet Gynecol. 2017;6:4671-6.

3. Fazal S, Poornima AP. A study on transfusion practice in obstetric hemorrhge in tertiary care center. Glob J Transfuse Med. 2018;3:41-5.

4. WHO recommendations on antenatal care for a positive pregnancy experience. WHO 2016.
Available at: https://apps.who.int/iris/bitstream /handle/10665/250796/9789241549912eng.pdf; sequence $=1$. Accessed on $18^{\text {th }}$ August 2019.

5. Madhushree D, Metgud MC, Patil K. Retrospective analysis of all patients undergoing blood transfusion in obstetrics at a Tertiary Care Hospital, Belgaum: A cross-sectional study. Indian J Health Sci Biomed Res. 2018;11:116-20.

6. Kawthalkar A, Kose V, Joshi S, Bhalerao A, Kumare B, Somalwar S. Blood transfusion in obstetrics and gynaecology: a retrospective analysis. Panacea J Med Sci. 2015:5(3);109-12.

7. National Family Health Survey (NFHS-4), 2015-16. Available at: http://rchiips.org/Nfhs/NFHS4Reports/Gujarat.pdf. Accessed on $25^{\text {th }}$ November 2019.

8. Adukauskienè D, Veikutienė A, Adukauskaitė A, Veikutis V, Rimaitis K. The usage of blood components in obstetrics. Medicina. 2010;46(8):561-7.

9. Chowdhury F, Akhter S, Islam A, Rayen J, Begum $\mathrm{N}$, Begum F. Evaluation of blood transfusion practices in obstetrics and gynecology in a tertiary hospital in Bangladesh. J Bangladesh College Phy Surg. 2016;34:9-14.

10. Patel VP, Patel RV, Shah PT, Patel CK. Study of role of blood transfusion in obstetric emergencies. Int J Reprod Contracept Obstet Gynecol. 2014;3:1002-5.

Cite this article as: Vasava DC, Thaker RV, Tyagi AA, Patel FP. Analysis of transfusion of blood and blood products and their utilization pattern at department of obstetrics of tertiary care hospital. Int J Reprod Contracept Obstet Gynecol 2020;9:261-5. 